\title{
CUIDANDO DE QUEM CUIDA ${ }^{1}$
}

\author{
Pedro R. Gil-Monte*
}

A exposição aos riscos de caráter psicosocial é uma das principais causas de acidentes, enfermidades e absenteísmo em profissionais, entre os quais se encontram as pessoas comprometidas em ocupações de ajuda. A síndrome de queimar-se pelo trabalho (SQT) ou burnout é uma resposta ao estresse laboral crônico, muito freqüente nestes profissionais e uma das principais patologias de origem psicosocial que os afetam, pois ocasiona uma importante taxa de absenteísmo e de abandono da profissão. O burnout é também uma das principais causas da deterioração na qualidade dos cuidados que estes grupos oferecem.

A obra, Quem cuida também merece cuidados: Conhecendo e prevenindo o Burnout, elaborado por Benevides-Pereira e Neves, da Editora da Universidade Estadual de Maringá, descreve de maneira clara e precisa em que consiste esta patologia. A estrutura e o desenho gráfico que apresenta a obra deixa muito fácil sua leitura, sua compreensão e sua função de divulgação, tornando-a atrativa para os profissionais dos setores ocupacionais dedicados ao cuidar, como é o caso das pessoas que trabalham com pacientes soropositivos, aos quais se dirige o documento. A obra está estruturada em sete partes, mediante as quais, ao longo de quatorze páginas, se apresenta uma revisão dos principais sintomas do burnout, uma definição de estresse e da síndrome de burnout, para concluir explicando algumas estratégias de enfrentamento e prevenção. Além do mais, se oferecem referências bibliográficas para que o leitor possa ampliar seus conhecimentos sobre esta patologia.
$\mathrm{Na}$ primeira parte (Introdução), as autoras justificam brevemente a necessidade de se elaborar este tipo de documento, com o intuito de informar os profissionais que trabalham com pessoas soropositivas das conseqüências que os riscos psicossociais associados às tarefas de cuidar têm sobre sua saúde e da necessidade de estar alerta para preveni-los. Também advertem que o documento tem caráter informativo, não é um manual de auto-ajuda.

$\mathrm{Na}$ segunda parte do documento (Você já percebeu?), utilizando a interrogação como técnica para chamar a atenção do leitor e despertar seu interesse, apresentam uma serie de sintomas do burnout. De maneira muito breve, no entanto precisa, as autoras descrevem como os diferentes planos da psique (emocional, cognitivo, atitudinal, comportamental) são afetados no individuo, alguns dos principais sintomas do burnout, ao mesmo tempo em que os advertem que sua saúde pode ver-se comprometida. As autoras, utilizando uma linguagem mais técnica, entretanto de fácil compreensão, passam a explicar em duas novas seções ( $O$ que é o estresse?, $O$ que é o burnout?), o que é o estresse, entendido como resultado de um processo transacional no qual as demandas do entorno excedem os recursos do individuo, o que é o burnout, e sua relação com o estresse laboral crônico. Junto com a descrição dos sintomas utilizados habitualmente para o diagnóstico psicométrico do burnout, as autoras apresentam outros sintomas do tipo psicossomático, comportamental e psíquico.

1 Benevides-Pereira, A. M. T. \& Alves R. N. (2003) Quem cuida também merece cuidados: conhecendo e prevenindo o burnout. Maringá: Eduem.

* Doctor y Profesor Asociado da Unidad de Investigación Psicosocial de la Conducta Organizacional (UNIPSICO), Facultad de Psicología (Universidad de Valencia). 
O resto do documento está direcionado a oferecer ao leitor uma série de estratégias para prevenir o burnout e enfrentar seus transtornos. Na quinta parte (Como enfrentar o burnout?) recomendam uma série de hábitos para prevenir a aparição do burnout. Adotando uma orientação cognitivo-conductual, as autoras aconselham a realização de processos de autoanálise para identificar a aparição dos sintomas e assim antecipar-se ao seu progresso. Ainda, consideram que se devem estabelecer processos de comunicação adequados nas organizações e, em especial, oferecer e receber apoio social no trabalho. Também assinalam a importância de se adotar um estilo de vida saudável e de realizar períodos de descanso.

Na parte seis (Técnicas de Relaxamento) e na sete (Técnicas de Alongamento) oferecem uma serie de indicações muito simples para ajudar os cuidadores a relaxar e se aliviar dos sintomas de tensão e, concomitantemente, lhes recomendam que dediquem alguns minutos de sua jornada ocupacional à prática de relaxamento. As autoras concluem, ressaltando a importância de consultar profissionais qualificados e especialistas no diagnóstico e tratamento do burnout nos casos em que o cuidador suspeite estar desenvolvendo esta patologia.

Esta obra constitui uma contribuição essencial para a prevenção de riscos no trabalho. Devido a seu caráter de divulgação, também cumpre uma função social muito importante, pois contribui para a formação em saúde ocupacional de um grande número de pessoas comprometidas nas atividades do cuidar, e não somente para aquelas que trabalham com pessoas soropositivas.

Endereço para correspondência: Pedro R. Gil-Monte, Unidad de Investigación Psicosocial de la Conducta Organizacional (UNIPSICO), Facultad de Psicología (Universidad de Valencia). Avda. Blasco Ibáñez, 21, 46010 Valencia, España. E-mail: pedro.gil-monte@uv.es 